\title{
DISTRIBUIÇÃO ESPACIAL DA MIGRAÇÃO INTERESTADUAL QUALIFICADA NO BRASIL
}

Luanna Pereira de Morais ${ }^{1}$ Silvana Queiroz Nunes ${ }^{2}$

\begin{abstract}
Resumo
O presente trabalho tem como objetivo analisar a migração interestadual qualificada entre os vinte e sete estados do Brasil, nos quinquênios de 1986/1991, 1995/2000 e 2005/2010. Para tanto, inicialmente, faz-se a contextualização de pesquisas na literatura internacional e nacional sobre o fenômeno da fuga de cérebros, caracterizado como a migração de indivíduos qualificados de um local para outro que ofereça melhores condições de trabalho, renda, estudo, habitação etc. A principal fonte de informações são os microdados das amostras dos Censos Demográficos de 1991, 2000 e 2010. Os principais resultados mostram, entre 2000 e 2010, aumento de cerca de 180.000 indivíduos qualificados migrando entre os estados do Brasil, com a maioria, em todos os anos analisados, se dirigindo preferencialmente para a região CentroOeste, notadamente para o Distrito Federal. Por outro lado, a região Sudeste foi a que mais perdeu migrantes qualificados, especialmente o estado do Rio de Janeiro.
\end{abstract}

Palavras-Chave: Migração qualificada; Brasil; Distribuição Espacial.

\section{SPATIAL DISTRIBUTION OF QUALIFIED INTERESTADUAL MIGRATION IN BRAZIL}

\begin{abstract}
This paper aims to analyze the qualified public interest among the twenty-seven states of Brazil, in the five-year periods of 1986/1991, 1995/2000 and 2005/2010. Therefore, allowed, it makes a contextualization of researches in the international and national literature on the brain drain phenomenon, as the use of filters of use of a place for other better working conditions, income, study, accommodation etc. The main source of information is the microdata of the demographic densities of 1991, 2000 and 2010. The main results shown, between 2000 and 2010, increase about 180,000, when they are migrated between the states of Brazil, with the majority, in all the years analyzed, going preferably for the Midwest region, notably for the Federal District. On the other hand, the Southeast region was the one that lost most migrants, especially the state of Rio de Janeiro.
\end{abstract}

Keywords: Qualified migration; Brazil; Spatial distribution.

\footnotetext{
${ }^{1}$ Economista. Mestranda em Ciência da Propriedade Intelectual pela Universidade Federal de Sergipe (UFS) São Cristóvão-Sergipe-Brasil. Email: luannapereiramorais@gmail.com

2 Economista. Doutora em Demografia pela Universidade de Campinas (UNICAMP). Pós-doutora pelo PPGDem/UFRN. Professora Adjunta do Departamento de Economia da Universidade Regional do Cariri (URCA) Crato-Ceará-Brasil.
} 


\section{DISTRIBUCIÓN ESPACIAL DE LA MIGRACIÓN INTERESTADUAL CALIFICADA EN BRASIL}

\section{Resumen}

El artículo tiene como objetivo analisar la migración intraestatal cualificada entre los veintisiete estados de Brasil, a lo largo de los quinquenios de 1986/1991, 1995/2000 e 2005/2010. Por ello, inicialmente, se plantea el contexto de investigación em la literatura internacional y nacional sobre el fenómeno de escape de cerebros, caracterizado como la migración de individuos cualificados de un local para el outro que ofrezca mejores condiciones de trabajo, renta, estudio, vivienda, etc. El principal camino de informaciones son los microdatos de las muestras de los Censos Demográficos de 1991, 2000 e 2010. Los principales resultados presentan, entre 2000 y 2010, aumento alrededor de 180.000 individuos cualificados migrando entre los estados de Brasil, con la mayoría, en todos los años analizados, procediendo preferentemente a la región Centro-Oeste, estraordinariamente al Distrito Federal. Sin embargo, la región Sudeste fue la que más perdió migrantes cualificados expresamente el estado de Rio de Janeiro.

Palabras - Clave: Migración calificada; Brasil; Distribución espacial.

\section{INTRODUÇÃO}

O fenômeno da fuga de cérebros ("brain drain") caracteriza-se como a transferência de recursos na forma de capital humano entre o local de origem e o de destino, a partir da migração de indivíduos qualificados de um local para outro que ofereça melhores condições de trabalho, rendimento, estudo, moradia, entre outros. Neste sentido, neste estudo, a mão de obra qualificada é caracterizada por pessoas com nível superior completo, conforme é abordado nos trabalhos de Özden (2006) e Da Mata et al. (2007).

Um dos primeiros estudiosos da relação entre migração interna e capital humano foi Sjaastad (1962). Para o autor, a migração representa um investimento em capital humano, que deve proporcionar melhoria na condição de vida e colocação no mercado de trabalho para os indivíduos e/ou migrantes. Portanto, o indivíduo ao decidir migrar considera os gastos monetários e não monetários e se os custos com a migração serão recuperados.

Portes (1976), no estudo sobre fuga de cérebros afirma que os determinantes da migração de indivíduos qualificados estão relacionados ao melhor treinamento, menor carga de trabalho e "fuga" para lugares mais valorizados. Baixo nível de criminalidade e menor desigualdade social da região também são elencados como fatores na escolha desses lugares.

A migração de cérebros é uma tendência cada vez mais dominante nas migrações internacionais, sobretudo, porque os países desenvolvidos são os que propiciam maiores rendimentos aos profissionais qualificados, atraindo os melhores profissionais/trabalhadores de países menos desenvolvidos (MIYAGIWA, 1991; PORTES, 1976). Assim, as diferenças dos 
níveis de desenvolvimentos entre os países influenciam as migrações (SOLIMANO, 2006) e aumenta o "gap" e/ou diferença no nível de desenvolvimento entre o país de origem e o país de destino, bem como entre as regiões e estados de um mesmo país.

No contexto internacional foram realizados diversos estudos sobre a fuga de cérebros, Lee e Kim (2009) analisam o retorno para a Coreia do Sul de doutores procedentes dos Estados Unidos. Já Delicado (2010) pesquisou o regresso e reingresso de cientistas de Portugal que foram estudar fora do país. Em nível nacional, Schwartzman $(1972,1978)$ analisou os fatores que atraíram os brasileiros para o exterior. Por outro lado, Sabbadini e Azzoni (2006) verificaram a migração interestadual dos indivíduos com mestrado e doutorado. Em contrapartida, Taveira, Gonçalves e Freguglia (2011) realizaram estudo sobre os migrantes qualificados da indústria entre os municípios do estado de São Paulo. Já Serrano et al. (2013) selecionaram duas microrregiões de cada macrorregião brasileira e dividiram por aquelas que mais perderam indivíduos de alta escolaridade e as que mais ganharam. Por sua vez, Torres (2016) abordou a migração de cérebros nos municípios do Brasil. Cabe salientar que outros autores, discutidos com mais detalhes na seção 2 deste trabalho, analisaram diversos cenários para esse tipo de migração. Entretanto, este estudo busca contribuir com o preenchimento de lacunas existentes, no contexto das migrações internas e de relativa desconcentração da atividade econômica e geração de postos de trabalho em áreas menos desenvolvidas.

Desse modo, tem-se como objetivo analisar a migração qualificada entre as 26 Unidades da Federação e o Distrito Federal que compõe o território brasileiro, a partir do volume da Imigração, Emigração, Saldo Migratório e o Índice de Eficácia Migratória (IEM), entre os interregnos de 1986/1991, 1995/2000 e 2005/2010, a partir do quesito data fixa. Esta informação/quesito diz respeito ao lugar de residência dos indivíduos exatamente cinco anos antes da coleta do Censo Demográfico. É importante destacar que tal quesito foi adotado pela primeira vez no Censo de 1991.

No tocante a estrutura do trabalho, além desta introdução e das considerações finais, o mesmo conta com mais três seções: a segunda contextualiza estudos sobre a migração qualificada em nível internacional e nacional. A terceira descreve os procedimentos metodológicos para alcançar os objetivos propostos. Por fim, a quarta seção analisa a migração interestadual qualificada no Brasil. 


\section{REFERENCIAL TEÓRICO}

\section{Migração qualificada: estudos internacionais}

Como teórico da economia neoclássica, Sjaastad (1962) aborda a migração interna fundamentada no aspecto econômico. Sendo assim, como ser racional, a tomada de decisão de migrar é baseada em fatores que geram custos monetários (despesas com moradia, transporte e alimentação), retornos monetários (remunerações), e custos não monetários (psicológicos, como abandono da cidade de origem e da família, preferência pela nova localidade). Portanto, para o autor, a decisão de migrar está relacionada ao custo-benefício, e a migração é um investimento em capital humano, que tem como finalidade a melhoria das condições de vida e do trabalho.

Portes (1976) foi um dos primeiros estudiosos sobre a fuga de cérebros. O autor constatou que, em geral, países mais pobres perdem profissionais qualificados para os países mais desenvolvidos. Além disso, apresentou três fatores determinantes para a migração de mão de obra qualificada que são: os determinantes primários, relacionados às desigualdades entre as localidades de naturalidade e de destino dos indivíduos; os determinantes secundários, considerados como a possibilidade das pessoas qualificadas serem inseridas no mercado de trabalho dos seus países de origem, devido a maior oferta de trabalho, sem que haja a necessidade de migrar por melhores condições; e os determinantes terciários, relacionados às características de qualificação, influências e círculo social. Dessa forma, quanto mais qualificados maiores são as chances desses profissionais migrarem para locais mais prósperos e com maiores chances de melhor remuneração.

O estudo de Miyagiwa (1991) destaca que países mais desenvolvidos podem oferecer rendimentos elevados para os profissionais qualificados, atraindo os melhores profissionais de países menos avançados. Além disso, as políticas empregadas para evitar as migrações dos indivíduos, apenas influenciam os menos qualificados, enquanto os mais qualificados continuam a migrar.

Por sua vez, Solimano (2006) enfatizou que a migração internacional de talentos pode ter importantes efeitos nos países de origem, nos países de destino e na sociedade como um todo. Para o autor, talento humano é um meio econômico e fator importante no desenvolvimento da ciência, tecnologia, negócios e cultura. A habilidade dos indivíduos faz com que eles se movam para países que haja incentivos econômicos, ainda assim, caso surjam condições adequadas e investimos nos países de origem, eventualmente esses indivíduos podem vir a 
retornar. Nesse contexto, as diferenças dos níveis de desenvolvimentos entre os países continuam como fatores de migração.

Já Özden (2006) desenvolveu um modelo teórico para investigar o desempenho do mercado de trabalho de migrantes qualificados e, em seguida, utiliza dados do Censo Demográfico dos Estados Unidos para uma análise empírica. Concluiu que o tipo de emprego que o migrante obtém é importante para influenciar o seu desempenho no país de destino. Ademais, grande parte da variação entre os países pode ser explicada por atributos do país de origem, que determinam a qualidade e a relevância do capital humano, como as despesas com o ensino superior e a fluência do inglês.

No estudo de análise transversal com 127 países, Beine, Docquier e Rapoport (2008) demonstraram que países com baixos níveis de taxas de capital e baixa taxa de migração de trabalhadores qualificados, são mais favoráveis para a fuga de cérebros. Por exemplo, pequenos países na África Subsaariana e América Central, têm elevada taxa de fuga de cérebros. Já países como a China, Índia e Brasil, parecem experimentar ganhos expressivos de trabalhadores qualificados, uma vez traduzidos em números, estes ganhos compensam as perdas, o que resulta num ganho global para os países em desenvolvimento. Os autores concluem que há mais perdedores do que vencedores, mas resulta em ganhos globais para os países em desenvolvimento.

Lee e Kim (2009) analisaram o retorno para a Coreia do Sul de doutores procedentes dos Estados Unidos. Ao avaliar as motivações dos mesmos, concluíram que a economia e as desigualdades entre as nações podem ajudar a explicar porque os estudantes coreanos optam por estudar nos EUA, e a sua decisão de retornar está associada a fatores não econômicos, como os laços familiares e as origens culturais.

Delicado (2010) estudou o regresso e reingresso de cientistas de Portugal que foram estudar fora do país, no período entre 2007 e 2009 . Concluiu que o número de pesquisadores nacionais que saem de Portugal é maior do que os estrangeiros que entram. Além disso, existem dois tipos de pesquisadores: primeiro, os mais antigos, compostos pelos docentes universitários que regressam para suas instituições de origem depois de completarem sua formação acadêmica; e o segundo tipo são os mais jovens, que não possuem nenhum vínculo com uma instituição portuguesa e saem devido a bolsas de estudos de doutorado sustentadas pelo governo de Portugal. No entanto, ainda existem algumas dificuldades no reingresso ao sistema científico, mesmo assim, os retornos são relevantes, pois possibilita que a produção científica 
se dinamize e haja um enriquecimento com as redes de colaboração internacional que foram formadas.

Haupt, Krieger e Lange (2013) analisaram como a migração de estudantes de um país menos desenvolvido para um mais desenvolvido altera a política de educação no país desenvolvido, e como isso afeta o capital humano e o bem-estar nos dois países. Os autores argumentam que há uma maior probabilidade de uma migração permanente, isto é, a permanecia de estudantes estrangeiros no país de acolhimento após a graduação, incentivados pelo país anfitrião com a melhoria constante na qualidade da educação, representado segundo os mesmos pelo aumento do capital humano e do bem-estar de todos os alunos, inclusive aqueles que retornam. Este efeito favorece os países desenvolvidos e com um impacto menor nos países em desenvolvimento.

\section{Migração qualificada - estudos nacionais}

A primeira pesquisa que trata da problemática da migração qualificada no Brasil foi realizada no início dos anos 1970, com o patrocínio do Instituto de Treinamento e Pesquisa das Nações Unidas (UNITAR). A mesma era uma pesquisa internacional, cujo principal objetivo era estudar o impacto do estudo universitário de indivíduos de países subdesenvolvidos em países desenvolvidos, e avaliar as probabilidades de retornarem para os seus países de origem ou de permanecerem no exterior (SCHWARTZMAN, 1972, 1978).

No Brasil, o projeto recebeu o nome de "projeto retorno" e foram entrevistadas quase 600 pessoas formadas no exterior. Como principais resultados, na América Latina, o Brasil é o país que mais receberá seus estudantes de volta. Ademais, a grande maioria dos brasileiros que foram estudar no exterior tinham bolsas de estudo, possuíam vínculo empregatício no Brasil, com isso, poucos permaneceram no exterior depois de terminarem os seus estudos, apenas $5 \%$ (SCHWARTZMAN, 1972, 1978).

Nessa mesma pesquisa, os fatores que atraíram os brasileiros para o exterior foram as melhores condições profissionais disponíveis (bibliotecas, equipamentos, etc.), e como os fatores para o retorno estão os psicológicos e familiares. Além disso, os brasileiros ao retornarem após os seus estudos no exterior, dirigiam-se aos estados do Rio de Janeiro e de São Paulo. A conclusão foi que nos anos 1970 não existia "brain drain" no Brasil (SCHWARTZMAN, 1972, 1978).

Guimarães (2002) aplicou 2.769 questionários a líderes de grupos de pesquisa, entre 1993 e 1999. Os perfis dos pesquisadores estudados eram formados ou em formação, cujo motivo do afastamento foi a realização de doutorado. Houve uma perda de 5,3 pesquisadores 
doutores em cada 100 novos colocados no mercado. Entre os maiores destinos estavam as regiões Sudeste e Sul, dado as melhores condições de trabalho e/ou salários. Para outras regiões geográficas, a migração foi de 780 pesquisadores, as escolhas foram por estados como Santa Catarina e o Paraná, mesmo estes não possuindo tradição científica.

Sabbadini e Azzoni (2006), através dos microdados do Censo Demográficos de 1991 e 2000, verificaram o processo de migração interestadual dos indivíduos qualificados, considerados pelos autores somente aqueles com mestrado e doutorado. Constataram que a renda, qualidade de vida e o número de pós-graduação das regiões são variáveis importantes no processo de atração dos indivíduos qualificados.

Da Mata et al (2007) realizou uma análise empírica para saber as principais características de uma cidade para atrair ou não os migrantes qualificados e concluiu que o dinamismo do mercado de trabalho, os menores níveis de violência, desigualdade social, a proximidade com o litoral e as variações climáticas se destacam.

Bezerra e Silveira Neto (2008), através dos dados do Censo Demográfico de 1991 e 2000, contataram que as regiões Sudeste e Sul, representado pelo estado de São Paulo, recebe a maior quantidade de migrantes qualificados, principalmente do Rio de Janeiro e do Rio Grande do Sul. Com relação as regiões Norte e Centro-Oeste, elas enviaram uma menor quantidade de migrantes qualificados. O Nordeste é um caso especial, não existe fuga de capital humano qualificado, como motivo está a já escassa mão de obra qualificada, que é segurada com vantajosos incentivos para permanecerem em seu estado de origem.

Em um estudo específico sobre os migrantes qualificados da indústria entre os municípios do estado de São Paulo, entre os anos de 1999 e 2002, Taveira, Gonçalves e Freguglia (2011) concluíram que a capital paulista continua sendo o mais importante receptor e emissor de migrantes qualificados, nos setores de maior intensidade tecnológica. Muitos trabalhadores ao migrar para outros municípios ou mudar de setor, buscam aqueles com o mesmo nível tecnológico do anterior ou saem de um nível tecnológico intensivo para um não intensivo, no entanto, não é verificado o movimento contrário devido ao conhecimento tecnológico entre os indivíduos. A maior parte desses migrantes deixaram as metrópoles e procuram cidades de médio ou pequeno porte, em busca de melhor qualidade de vida, devido a fatores como aglomerações, custo de vida, congestionamentos, entre outros.

A partir dos microdados da Rais-Migra, e ao considerar indivíduos com curso superior completo que mudaram das microrregiões brasileiras nos anos de 1999, 2000 e 2001, Gonçalves, Ribeiro e Freguglia (2012) constataram que entre os atrativos para a migração de 
trabalhadores mais qualificados estão a localidade, oportunidade de emprego, renda per capita e IDH (Índice de Desenvolvimento Humano). Contudo, a inovação tecnológica não seria um motivo para a migração dos profissionais, pois no Brasil a inovação é uma variável negativa para a migração, devido a concentração nas regiões mais desenvolvidas, que demonstraram fatores de repulsão de trabalhadores.

Serrano et al (2013), utilizaram os fluxos migratórios captados nos Censos Demográficos de 1991, 2000 e 2010, e selecionaram duas microrregiões de cada macrorregião brasileira: as que mais perderam população de alta escolaridade e as que mais ganharam. $\mathrm{Na}$ região Norte, a microrregião de Belém é considerada a que possui as maiores saídas e Porto Nacional (TO) apresenta significativa atração de indivíduos qualificados; para a região Nordeste, João Pessoa (PB) se sobressaiu com o maior saldo migratório e Ilhéus-Itabuna (BA) destacou-se por ter a maior evasão de indivíduos com alta escolaridade; no Sudeste, o destaque foi a microrregião de Belo Horizonte (MG) que apresentou característica de absorção de pessoas com nível escolar superior, e com relação a São Paulo (SP), o mesmo é considerado como distribuidor, isto é, doador, e o Rio de Janeiro (RJ) também apresenta evasões de mão de obra qualificada para o Brasil; na região Sul, Florianópolis (SC) mostrou- se como concentradora, e Santa Maria (RS), aparece com o terceiro saldo de emigração de pessoas com alta escolaridade, ficando atrás somente de São Paulo e Rio de Janeiro. E, finalmente, Brasília (DF) se destaca por ser a microrregião que mais recebe migrantes com o ensino superior completo ou em formação.

A partir da PNAD de 2001, 2006 e 2011, Campos (2014) apontou que os migrantes qualificados são do sexo masculino, branco, solteiro, jovem e com salários elevados. Concluiu que para o estado do Espírito Santo, as evidências com o modelo logit estimado para o ano de 2011, demonstrou que o mesmo está tornando-se um polo de atração de mão de obra qualificada, sendo que os principais estados que mais atraem profissionais qualificados são os estados de São Paulo e o Distrito Federal.

Para o estado do Paraná, Scheneider e Henrique (2015), através da avaliação dos microdados do Censo Demográfico 2010, concluíram que 60 mil pessoas com ensino superior se deslocaram dentro do estado, e as microrregiões de Curitiba e Paranaguá possuem os maiores números de profissionais com alta qualificação. Ainda segundo os dados, 38.300 mil pessoas imigraram de outras regiões do Brasil para o Paraná, em contrapartida, 43.900 mil pessoas com ensino superior no Paraná realizaram o movimento reverso, gerando um saldo negativo de 5.000 pessoas, constatando que existe fuga de cérebros no Paraná. A saber, as regiões com maior 
concentração de indivíduos com alta qualificação dispõem de maiores taxas de crescimento de produtividade, redução da desigualdade da renda e aumento na qualidade de vida, o que incentiva o desenvolvimento econômico.

Em um estudo recente sobre migração de cérebros nos municípios do Brasil, foram escritos em dois ensaios, o primeiro sobre o impacto da produtividade do trabalho e o segundo os efeitos sobre a acumulação do capital humano, sendo essa abordagem realizada por Torres (2016), por meio do Censo Demográfico de 2010. Os resultados demonstraram que a taxa de emigração qualificada tem relação inversa com a variação no estoque de capital humano, a causa pode estar relacionada ao acesso a educação no Brasil. Constataram que os munícipios de pequeno porte, Aliança do Tocantins, Viçosa e Damôlandia apresentam as maiores perdas de capital humano, já os maiores ganhadores foram representados por quatro capitais: Vitória, Aracaju, Palmas e São Paulo. Portanto, os municípios menores são os menos beneficiados com a migração de mão de obra qualificada.

Com relação a migração qualificada, tanto nos estudos internacionais quanto nos nacionais, constatou-se que os migrantes procuram localidades com melhores níveis salariais, maiores oportunidades de trabalho e melhor qualidade de vida. Diante disso, este trabalho procura sanar a lacuna de estudos no Brasil que, em geral, abordam essa temática a partir do fluxo regional e metropolitano e, com isso, mensurar a migração qualificada a partir do fluxo interestadual e detalhar as especificidades dessa dinâmica, dado a grande heterogeneidade brasileira segundo Unidade da Federação.

\section{PROCEDIMENTOS METODOLÓGICOS}

\section{Recorte geográfico}

A área de estudo deste trabalho abrange as 26 Unidades da Federação e o Distrito Federal que compõe o território brasileiro, dado que se pretende analisar a migração interestadual qualificada, entre 1986/1991, 1995/2000 e 2005/2010.

\section{Fonte de dados e recorte temporal}

A principal fonte de dados são os microdados das amostras dos Censos Demográficos de 1991, 2000 e 2010, levantados pelo Instituto Brasileiro de Geografia e Estatística (IBGE). O recorte temporal compreende precisamente os quinquênios de 1986/1991, 1995/2000 e 2005/2010. A escolha desse interregno é devida o quesito data fixa ser adotado pela primeira vez a partir do Censo Demográfico de 1991. Tal quesito diz respeito ao lugar de residência dos indivíduos exatamente cinco anos antes da coleta do Censo Demográfico. Portanto, será 
possível analisar as inflexões e tendências da migração interestadual qualificada durante três interregnos consecutivos.

\section{Definições adotadas no estudo}

Quanto as categorias em análise, as populações são classificadas em:

Imigrante qualificado - indivíduo com nível superior completo que, na data de referência do Censo Demográfico, residia em um estado brasileiro, mas em uma data fixa (exatamente cinco anos antes do recenseamento) morava em outro estado do Brasil.

Emigrante qualificado- indivíduo com nível superior completo que, na data de referência do Censo Demográfico, residia em outro estado, mas em uma data fixa (exatamente cinco anos antes do recenseamento) morava em um dos estados do Brasil.

Saldo migratório - representa a diferença entre o total de imigrantes e de emigrantes qualificados.

É importante frisar que o quesito data fixa diz respeito aos anos de 1986, 1995 e 2005 (cinco anos antes do recenseamento), e as informações sobre o nível de instrução referem-se aos anos de 1991, 2000 e 2010 (data de realização do Censo), respectivamente. Portanto, alguns indivíduos possivelmente migraram antes de completar o ensino superior.

Ademais, para melhor compreender e verificar se os estados perdem, ganham ou têm volume de entrada e saída praticamente semelhantes de migrantes qualificados foi utilizado o Índice de Eficácia Migratória (IEM), que varia entre -1,00 e +1,00. Tal índice é calculado por meio do quociente entre a Migração Líquida (I-E) e a Migração Bruta (I+E).

$$
\mathrm{IEM}=\frac{(\mathrm{I}-\mathrm{E})}{(\mathrm{I}+\mathrm{E})}
$$

Através desse indicador (Oliveira; Oliveira, 2011; Baeninger, 2012) é possível identificar se os estados ganham (entra mais migrante do que sai), perdem (sai mais migrante do que entra) ou se a quantidade de entrada e saída de migrantes qualificados é praticamente semelhante (rotatividade migratória).

i) -1,00 a -0,13: representa área de perda migratória;

ii) -0,12 a 0,12: representa área de rotatividade migratória;

iii) 0,13 a 1,00: representa área de retenção migratória. 


\section{Tratamento das informações}

No tocante a extração das informações, o software SPSS (Statistical Package for the Social Sciense, versão 21.0) foi a ferramenta estatística utilizada. A confecção de mapas temáticos foi realizada com o uso do software QGIS.

\section{RESULTADOS E DISCUSSÕES}

\section{Migração qualificada: o fluxo interestadual brasileiro}

Esta seção analisa o volume de imigrantes e emigrantes interestaduais qualificados no Brasil, nos interregnos de 1986/1991, 1995/2000 e 2005/2010, verificando o saldo migratório, para analisar a perda ou ganho, entre os estados do país.

Os resultados na Tabela 1 mostram que no quinquênio de 1986/1991, o Brasil apresentou uma migração interestadual qualificada de 239.040 pessoas e, no período de 1995/2000, aumenta para 300.285 e, no interregno 2005/2010, obteve um aumento expressivo para 486.448 migrantes. Portanto, entre os dois últimos interregnos em estudo, houve um aumento de cerca de 180.000 indivíduos qualificados migrando entre os estados do país.

Corroborando com os resultados expostos, Serrano et al. (2013) justifica que a migração é um fenômeno importante para a distribuição espacial da população pelo território brasileiro, especialmente de indivíduos qualificadas. Lembrando que segundo o autor, no Brasil, ainda existe carência de indivíduos com nível superior, além de estarem mal distribuídos pelas Unidades da Federação.

Em nível regional, no interregno de 1986/1991, a região Centro-Oeste obteve uma entrada de 37.777 imigrantes $(15,80 \%)$ e saída de 27.348 emigrantes $(11,44 \%)$, apresentando o maior saldo migratório positivo (10.429) entre as regiões do país. A região Norte é a segunda que mais atrai migrantes qualificados, mas com valores menos significativos, ao configurar com um saldo positivo de 972 pessoas. Por outro lado, o Sudeste apresentou o maior saldo negativo (-7.528), o Nordeste o segundo maior saldo negativo (-3.026), e o Sul obteve o menor saldo negativo (-847).

Segundo Golgher, Rosa e Araújo Júnior (2005), as características regionais e os aspectos individuais têm influência decisiva sobre os determinantes da migração. Isto porque, em geral, o migrante decide mudar do local de residência em busca de uma melhor posição no mercado de trabalho, maiores rendimentos, como também lugares com melhor qualidade de vida e melhores oportunidades educacionais. Esta dinâmica tem efeitos sobre a vida dos indivíduos qualificados e sobre as regiões/estados que atraem esse tipo de mão de obra. 
Já no período de 1995/2000, as regiões Centro-Oeste (16.471), Norte (4.427), Sul (1.594), e Nordeste (1.248) alcançaram saldos migratórios positivos, com somente o Sudeste mantendo negativo e aumentando expressivamente (-23.740), devido a entrada de 113.906 imigrantes (37,93\%) e a saída de 137.646 emigrantes (45,84\%). Segundo Sabaddini e Azzoni, “esses movimentos não têm, relativamente às populações estaduais de pós graduados, como maiores beneficiários os estados do Sudeste, o que sugere um sentido desconcentrador dessa migração" (2006, p. 19).

Esse resultado coincide com um período no qual indústrias do Sul e do Sudeste buscaram resolver problemas de deseconomias de aglomeração nos grandes centros, saindo de espaços saturados para baixar custos de produção em outras regiões. Empresas intensivas em mão-de-obra, como as indústrias têxteis e de calçados, deslocaram-se para o Norte e notadamente o Nordeste, aproveitando os salários mais baixos, menos sindicalização, aproximação geográfica com o mercado internacional (Europa e Ásia), proximidade com fontes de matéria-prima, além da política de 'guerra fiscal'.

Quanto ao último quinquênio em estudo (2005/2010), somente o Centro-Oeste (25.537) e a região Norte (9.440) obtiveram saldo migratório positivo na atração de profissionais qualificados, mantendo a tendência constatada no interregno 1986/1991. Por outro lado, mais uma vez, o Sudeste demonstrou o maior saldo migratório negativo (- 25.678 indivíduos), mesmo sendo a região que apresenta o maior fluxo migratório, com a chegada de 181.213 imigrantes (37,25\%), mas saem 206.891 emigrantes (42,53\%). Já a região Sul, teve um saldo negativo de -6.559 pessoas. Com relação ao Nordeste, o saldo passou a ser negativo em -2.740 pessoas qualificadas. Entretanto, quando comparado às regiões que apresentam saldo negativo, o Nordeste têm os menores valores.

Conforme assinala Carvalho (2010, p. 4), o Nordeste obteve uma excelente colocação devido a fatores ocorridos nos anos 1990:

\footnotetext{
Nessa época, em meio a uma fase marcada pelo processo de liberalização da economia nacional e pela ausência de uma política de desenvolvimento industrial, com o esvaziamento da instituição coordenadora do planejamento regional, os maiores estados nordestinos, como Bahia, Ceará e Pernambuco, iniciaram uma estratégia de concessão de incentivos, a conhecida "guerra fiscal". Essa política de atração de indústrias, por meio da renúncia dos tributos, logo depois seria adotada pelos demais estados.
}

Em nível estadual, verifica-se por meio do ranking na Tabela 1 que, entre 1986/1991, os maiores saldos positivos de migrantes qualificados pertenciam a São Paulo $\left(1^{\circ}\right)$, Santa Catarina $\left(2^{\circ}\right)$ e Mato Grosso ( $\left.3^{\circ}\right)$. Por região, no Norte, o estado de Tocantins $\left(6^{\circ}\right)$; no Nordeste, 
o Rio Grande do Norte $\left(7^{\circ}\right)$; no Sudeste, o estado de São Paulo $\left(1^{\circ}\right)$; no Sul, o estado de Santa Catarina $\left(2^{\circ}\right)$; e no Centro-Oeste, Mato Grosso $\left(3^{\circ}\right)$ é o destaque na atratividade. Por outro lado, os estados que mais perderam foram Rio de Janeiro $\left(27^{\circ}\right)$ e Rio Grande do Sul $\left(26^{\circ}\right)$. No interregno de 1995/2000 houve alterações, o Distrito Federal (1º), Santa Catarina $\left(2^{\circ}\right)$ e o Ceará $\left(3^{\circ}\right)$ passaram a figurar com os maiores saldos positivos de migrantes qualificados do país. Em cada região, o melhor saldo do Norte ficou novamente por conta de Tocantins $\left(7^{\circ}\right)$; no Nordeste, o estado do Ceará $\left(3^{\circ}\right)$; no Sudeste, o Espírito Santo $\left(4^{\circ}\right)$; no Sul, o estado Santa Catarina $\left(2^{\circ}\right)$; e no Centro-Oeste, o Distrito Federal $\left(1^{\circ}\right)$. Com relação aos estados com as maiores perdas de migrantes qualificados, são eles: São Paulo $\left(27^{\circ}\right)$ e Rio de Janeiro $\left(26^{\circ}\right)$. 
MORAIS, Luanna Pereira de

Tabela 1 - Migração interestadual qualificada - Brasil - 1986/1991, 1995/2000 e 2005/2010

\begin{tabular}{|c|c|c|c|c|c|c|c|c|c|c|c|c|c|c|c|c|c|c|}
\hline \multirow{2}{*}{ UF } & \multicolumn{6}{|c|}{1991} & \multicolumn{6}{|c|}{2000} & \multicolumn{6}{|c|}{2010} \\
\hline & Imig. & $(\%)$ & Emig. & $(\%)$ & Saldo & Ranking & Imig. & $(\%)$ & Emig. & $(\%)$ & Saldo & Ranking & Imig. & $(\%)$ & Emig. & $(\%)$ & Saldo & Ranking \\
\hline RO & 3.258 & 1,36 & 3.626 & 1,52 & -368 & $18^{\circ}$ & 3.547 & 1,18 & 2.431 & 0,81 & 1.116 & $12^{\circ}$ & 6.304 & 1,30 & 3.900 & 0,80 & 2.404 & $8^{\circ}$ \\
\hline $\mathrm{AC}$ & 790 & 0,33 & 597 & 0,25 & 193 & $16^{\circ}$ & 905 & 0,30 & 791 & 0,26 & 114 & $18^{\circ}$ & 2.555 & 0,53 & 1.214 & 0,25 & 1.341 & $12^{\circ}$ \\
\hline $\mathrm{AM}$ & 2.851 & 1,19 & 3.420 & 1,43 & -569 & $21^{\circ}$ & 4.360 & 1,45 & 4.348 & 1,45 & 12 & $19^{\circ}$ & 6.885 & 1,42 & 7.259 & 1,49 & -374 & $17^{\circ}$ \\
\hline RR & 923 & 0,39 & 497 & 0,21 & 426 & $11^{\circ}$ & 1.601 & 0,53 & 1.004 & 0,33 & 597 & $14^{\circ}$ & 2.474 & 0,51 & 1.325 & 0,27 & 1.149 & $13^{\circ}$ \\
\hline PA & 4.399 & 1,84 & 6.023 & 2,52 & -1.624 & $24^{\circ}$ & 6.587 & 2,19 & 7.775 & 2,59 & -1.188 & $22^{\circ}$ & 12.267 & 2,52 & 11.850 & 2,44 & 417 & $15^{\circ}$ \\
\hline AP & 858 & 0,36 & 453 & 0,19 & 405 & $12^{\circ}$ & 1.937 & 0,65 & 596 & 0,20 & 1.341 & $9^{\circ}$ & 2.905 & 0,60 & 1.362 & 0,28 & 1.543 & $11^{\circ}$ \\
\hline TO & 3.268 & 1,37 & 759 & 0,32 & 2.509 & $6^{\circ}$ & 4.314 & 1,44 & 1.879 & 0,63 & 2.435 & $7^{\circ}$ & 7.890 & 1,62 & 4.930 & 1,01 & 2.960 & $7^{\circ}$ \\
\hline NO & 16.347 & 6,84 & 15.375 & 6,43 & 972 & & 23.251 & 7,74 & 18.824 & 6,27 & 4.427 & & 41.280 & 8,49 & 31.840 & 6,55 & 9.440 & \\
\hline MA & 2.925 & 1,22 & 3.367 & 1,41 & -442 & $20^{\circ}$ & 3.860 & 1,29 & 3.539 & 1,18 & 321 & $17^{\circ}$ & 7.587 & 1,56 & 8.027 & 1,65 & -440 & $18^{\circ}$ \\
\hline PI & 1.808 & 0,76 & 2.184 & 0,91 & -376 & $19^{\circ}$ & 2.164 & 0,72 & 2.386 & 0,79 & -222 & $20^{\circ}$ & 4.018 & 0,83 & 6.752 & 1,39 & -2.734 & $23^{\circ}$ \\
\hline $\mathrm{CE}$ & 5.078 & 2,12 & 6.523 & 2,73 & -1.445 & $22^{\circ}$ & 9.605 & 3,20 & 5.894 & 1,96 & 3.711 & $3^{\circ}$ & 10.679 & 2,20 & 11.746 & 2,41 & -1.067 & $20^{\circ}$ \\
\hline RN & 4.550 & 1,90 & 2.522 & 1,06 & 2.028 & $7^{\circ}$ & 5.208 & 1,73 & 3.890 & 1,30 & 1.318 & $10^{\circ}$ & 7.651 & 1,57 & 6.024 & 1,24 & 1.627 & $10^{\circ}$ \\
\hline PB & 3.765 & 1,58 & 5.339 & 2,23 & -1.574 & $23^{\circ}$ & 4.472 & 1,49 & 7.294 & 2,43 & -2.822 & $24^{\circ}$ & 9.427 & 1,94 & 8.488 & 1,74 & 939 & $14^{\circ}$ \\
\hline $\mathrm{PE}$ & 7.946 & 3,32 & 10.042 & 4,20 & -2.096 & $25^{\circ}$ & 9.571 & 3,19 & 12.332 & 4,11 & -2.761 & $23^{\circ}$ & 14.862 & 3,06 & 16.621 & 3,42 & -1.759 & $22^{\circ}$ \\
\hline $\mathrm{AL}$ & 3.084 & 1,29 & 2.890 & 1,21 & 194 & $15^{\circ}$ & 2.584 & 0,86 & 3.074 & 1,02 & -490 & $21^{\circ}$ & 4.248 & 0,87 & 4.988 & 1,03 & -740 & $19^{\circ}$ \\
\hline SE & 2.255 & 0,94 & 1.703 & 0,71 & 552 & $10^{\circ}$ & 2.585 & 0,86 & 2.016 & 0,67 & 569 & $15^{\circ}$ & 5.536 & 1,14 & 3.847 & 0,79 & 1.689 & $9^{\circ}$ \\
\hline BA & 10.095 & 4,22 & 9.962 & 4,17 & 133 & $17^{\circ}$ & 13.455 & 4,48 & 11.831 & 3,94 & 1.624 & $8^{\circ}$ & 21.156 & 4,35 & 21.411 & 4,40 & -255 & $16^{\circ}$ \\
\hline $\mathrm{NE}$ & 41.506 & 17,36 & 44.532 & 18,63 & -3.026 & & 53.504 & 17,82 & 52.256 & 17,40 & 1.248 & & 85.164 & 17,51 & 87.904 & 18,07 & -2.740 & \\
\hline MG & 22.828 & 9,55 & 22.614 & 9,46 & 214 & $13^{\circ}$ & 30.064 & 10,01 & 29.419 & 9,80 & 645 & $13^{\circ}$ & 39.622 & 8,15 & 57.169 & 11,75 & -17.547 & $27^{\circ}$ \\
\hline ES & 6.491 & 2,72 & 5.438 & 2,27 & 1.053 & $9^{\circ}$ & 8.778 & 2,92 & 5.460 & 1,82 & 3.318 & $4^{\circ}$ & 12.839 & 2,64 & 9.762 & 2,01 & 3.077 & $5^{\circ}$ \\
\hline RJ & 20.657 & 8,64 & 36.477 & 15,26 & -15.820 & $27^{\circ}$ & 25.711 & 8,56 & 36.886 & 12,28 & -11.175 & $26^{\circ}$ & 40.184 & 8,26 & 50.240 & 10,33 & -10.056 & $25^{\circ}$ \\
\hline SP & 50.845 & 21,27 & 43.820 & 18,33 & 7.025 & $1^{\circ}$ & 49.353 & 16,44 & 65.881 & 21,94 & -16.528 & $27^{\circ}$ & 88.568 & 18,21 & 89.720 & 18,44 & -1.152 & $21^{\circ}$ \\
\hline SE & 100.821 & 42,18 & 108.349 & 45,33 & -7.528 & & 113.906 & 37,93 & 137.646 & 45,84 & -23.740 & & 181.213 & 37,25 & 206.891 & 42,53 & -25.678 & \\
\hline PR & 19.130 & 8,00 & 17.793 & 7,44 & 1.337 & $8^{\circ}$ & 23.866 & 7,95 & 22.572 & 7,52 & 1.294 & $11^{\circ}$ & 36.132 & 7,43 & 41.136 & 8,46 & -5.004 & $24^{\circ}$ \\
\hline SC & 13.589 & 5,68 & 7.601 & 3,18 & 5.988 & $2^{\circ}$ & 19.890 & 6,62 & 11.645 & 3,88 & 8.245 & $2^{\circ}$ & 35.442 & 7,29 & 22.561 & 4,64 & 12.881 & $2^{\circ}$ \\
\hline $\mathrm{RS}$ & 9.870 & 4,13 & 18.042 & 7,55 & -8.172 & $26^{\circ}$ & 12.708 & 4,23 & 20.653 & 6,88 & -7.945 & $25^{\circ}$ & 18.536 & 3,81 & 32.972 & 6,78 & -14.436 & $26^{\circ}$ \\
\hline SUL & 42.589 & 17,82 & 43.436 & 18,17 & -847 & & 56.464 & 18,80 & 54.870 & 18,27 & 1.594 & & 90.110 & 18,52 & 96.669 & 19,87 & -6.559 & \\
\hline MS & 7.631 & 3,19 & 4.846 & 2,03 & 2.785 & $5^{\circ}$ & 8.293 & 2,76 & 7.837 & 2,61 & 456 & $16^{\circ}$ & 13.678 & 2,81 & 10.713 & 2,20 & 2.965 & $6^{\circ}$ \\
\hline MT & 8.450 & 3,53 & 3.912 & 1,64 & 4.538 & $3^{\circ}$ & 9.241 & 3,08 & 6.174 & 2,06 & 3.067 & $5^{\circ}$ & 15.321 & 3,15 & 11.287 & 2,32 & 4.034 & $4^{\circ}$ \\
\hline GO & 9.163 & 3,83 & 6.261 & 2,62 & 2.902 & $4^{\circ}$ & 12.867 & 4,28 & 10.156 & 3,38 & 2.711 & $6^{\circ}$ & 22.334 & 4,59 & 18.177 & 3,74 & 4.157 & $3^{\circ}$ \\
\hline DF & 12.533 & 5,24 & 12.329 & 5,16 & 204 & $14^{\circ}$ & 22.759 & 7,58 & 12.522 & 4,17 & 10.237 & $1^{\circ}$ & 37.348 & 7,68 & 22.967 & 4,72 & 14.381 & $1^{\circ}$ \\
\hline $\mathrm{CO}$ & 37.777 & 15,80 & 27.348 & 11,44 & 10.429 & & 53.160 & 17,70 & 36.689 & 12,22 & 16.471 & & 88.681 & 18,23 & 63.144 & 12,98 & 25.537 & \\
\hline TOTAL & 239.040 & 100,00 & 239.040 & 100,00 & 0 & & 300.285 & 100,00 & 300.285 & 100,00 & 0 & & 486.448 & 100,00 & 486.448 & 100,00 & 0 & \\
\hline
\end{tabular}

Fonte: Elaboração própria a partir dos microdados das amostras dos Censos Demográficos 1991, 2000 e 2010 (IBGE). 

De acordo com Cunha e Baeninger (2005), a partir dos anos 1990 e 2000, São Paulo passou a ser emissor de migrantes interestaduais, devido às dificuldades enfrentadas na adaptação e/ou aumento na seletividade/exigência do mercado de trabalho, além do aumento no número de desempregados, consequência da desconcentração da atividade econômica e da expansão do sistema educacional para outras regiões do país, fazendo com que os migrantes se dirigissem para estados como o Ceará, Bahia, Pernambuco e Paraná, considerados expulsores de população mas, paulatinamente, foram arrefecendo as suas perdas.

No período de 2005/2010, constatam-se outros principais destinos para a mão de obra qualificada. Os maiores saldos positivos ficaram com o Distrito Federal (1 $\left.{ }^{\circ}\right)$, Santa Catarina $\left(2^{\circ}\right)$ e Goiás $\left(3^{\circ}\right)$. Segundo grande região, o Norte é representado mais uma vez por Tocantins $\left(7^{\circ}\right)$; o Sudeste pelo Espírito Santo $\left(5^{\circ}\right)$; no Sul, outra vez, por Santa Catarina $\left(2^{\circ}\right)$; no CentroOeste novamente pelo Distrito Federal $\left(1^{\circ}\right)$; e no Nordeste o destaque foi Sergipe $\left(9^{\circ}\right)$. Quanto aos estados que mais perderam migrantes qualificados, destacam-se Minas Gerais $\left(27^{\circ}\right)$ e Rio Grande do Sul $\left(26^{\circ}\right)$ (Tabela 1).

A explicação para o Distrito Federal ser o melhor colocado na atração de migrantes qualificados é devido Brasília, ao tornar-se a capital do Brasil, passa a receber repasses federais, cria oportunidades de empregos públicos, além ser um polo de conhecimento de referência nacional, com a Universidade de Brasília (UnB), e o grande número de cursos preparatórios para concursos e vestibulares (IPEA, 2014). Por sua vez, Santa Catarina possui um complexo industrial formado pelas cidades de Joinville, Blumenau, Florianópolis, Itajaí e Chapecó (GOULARTI, 2015), apresenta baixa taxa de desemprego, e se destaca positivamente nos indicadores sociais e demográficos.

Com relação aos estados que mais perdem migrantes qualificados, historicamente Minas Gerais figura com elevado êxodo rural e/ou perda populacional, com destinos principalmente para São Paulo, Rio de Janeiro e o Centro-Oeste (Carvalho; Rigotti, 2016; Brito; Horta, 2002), sendo resultado da falta de oportunidades de empregos, remuneração salarial menor e falta de investimentos no Estado, apesar dos avanços a partir dos anos 2000.

Por sua vez, o Rio Grande do Sul, de acordo com Jardim e Barcellos (2011), a perda de população é devido as configurações regionais com dinâmicas econômicas deprimidas e o esgotamento de áreas de produção agrícola em pequena propriedade no estado.

Já o Rio de Janeiro, identifica-se por um caráter estrutural, representado por todas as mudanças ocorridas no estado fluminense ao longo dos anos, como por exemplo, a perda da sede da capital do país para Brasília e de investimentos para outros estados. Com isso, altera-se 
o sentido da corrente migratória, ao passar de área de atração para perda de atratividade, além da saída para outros estados (OLIVEIRA; ERVATTI, 2012).

\section{Migração interestadual qualificada: área de perda, rotatividade e retenção migratória}

Com relação ao Índice de Eficácia Migratória (IEM), que aferi a capacidade da região/estado perder, manter e a rotatividade (vai e vem) de migrantes qualificados. No que concerne a classificação das regiões, no período 1986/1991 (Figura 1), a região considerada como área de retenção de migrantes qualificados foi somente o Centro-Oeste $(0,16)$, sendo as demais classificadas como áreas de rotatividade de migrantes qualificados. De acordo com Anônimo e Santos (2015, p. 33), "a partir do momento que o estado de Goiás despontou como uma das principais fronteiras agrícolas do país, e a crescente importância da sua indústria, essa área passou a se destacar como área de atração e retenção migratória nacional”.

No que se refere ao IEM dos estados, destacam-se como áreas de atração de migrantes qualificados no Norte o estado de Tocantins $(0,62)$; no Centro-Oeste o Mato Grosso $(0,37)$; no Nordeste o Rio Grande do Norte (0,29); e no Sul o estado de Santa Catarina (0,28). Já os estados classificados como áreas de rotatividade são: Minas Gerais $(0,00)$, Distrito Federal $(0,01)$, Rondônia $(-0,05)$ e Ceará $(-0,12)$. E os estados considerados como áreas de perdas migratórias foram: Rio Grande do Sul (-0,29), Rio de Janeiro (-0,28), Paraíba (-0,17) e Pará (-0,16).

\section{Figura 1 - Classificação do Índice de Eficácia Migratória - Brasil - 1986/1991}

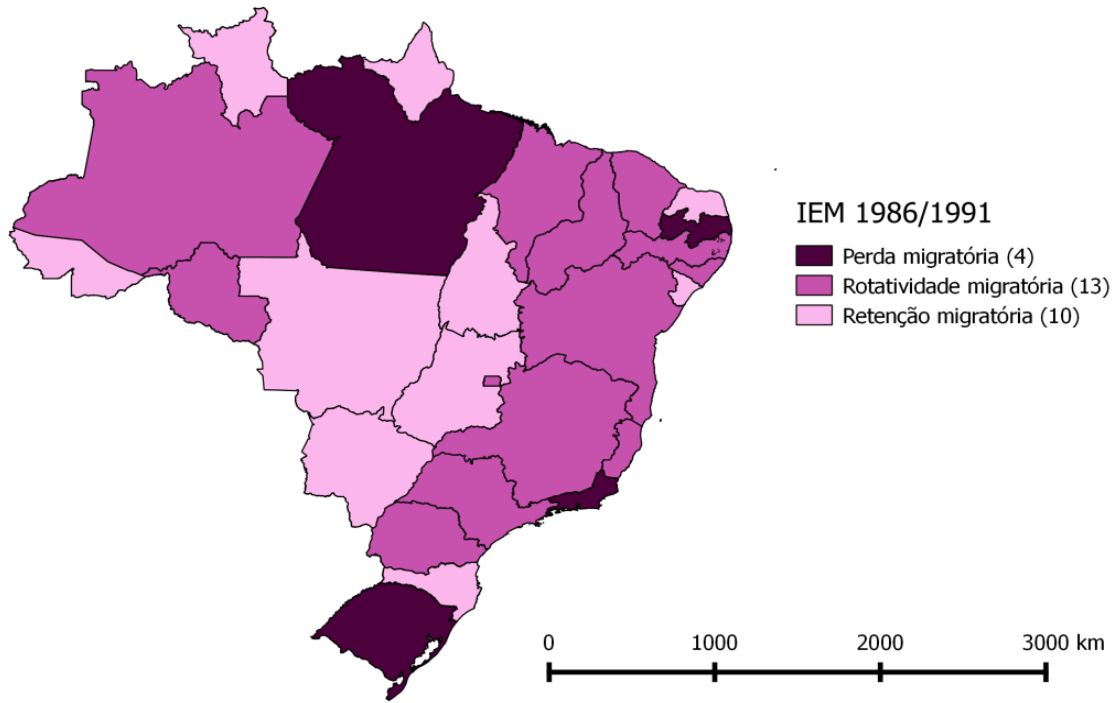

Fonte: Elaboração própria a partir dos microdados das amostras dos Censos Demográficos 1991 (IBGE). 
Durante o quinquênio 1995/2000 (Figura 2), o Centro-Oeste $(0,18)$ permanece como região de maior atração de migrantes qualificados, salienta-se que as outras regiões são classificadas como áreas de rotatividade de indivíduos qualificados. Com relação aos estados com as maiores retenções, são os seguintes: Amapá $(0,53)$ e Tocantins $(0,39)$ no Norte; Espírito Santo $(0,23)$ no Sudeste; Santa Catarina $(0,26)$ no Sul; Distrito Federal $(0,29)$ no Centro-Oeste; e o Ceará $(0,24)$ que apresentou o maior IEM do Nordeste. Para os estados caracterizados como áreas de perdas migratórias: Paraíba (-0,24), Rio Grande do Sul $(-0,24)$ e Rio de Janeiro $(-0,18)$.

Conforme Taveira e Almeida (2012), os municípios/estados concorrem entre si para atrair mais migrantes qualificados, pois eleva os níveis de inovação e desenvolvimento econômico das localidades. Para isso, é necessário por parte dessas regiões terem algumas características relevantes, como o PIB (Produto Interno Bruto) per capita, grau de industrialização elevado, transporte coletivo eficiente, baixos índices de violência, criminalidade e tráfego, tamanho da população e, sobretudo, a renda esperada.

Figura 2 - Classificação do Índice de Eficácia Migratória - Brasil - 1995/2000

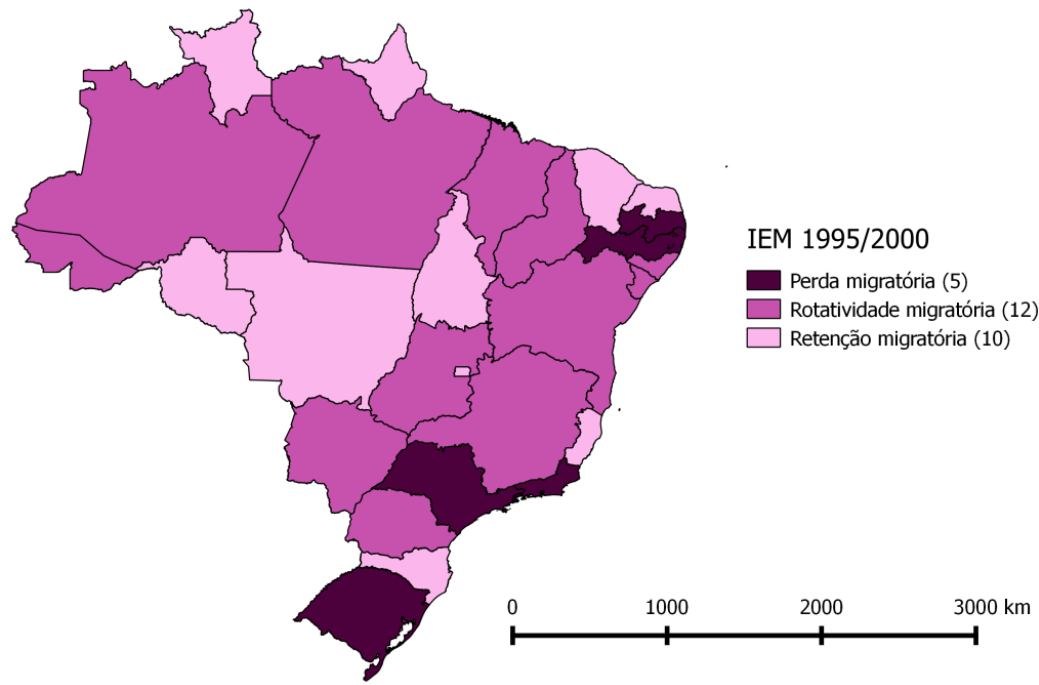

Fonte: Elaboração própria a partir dos microdados das amostras dos Censos Demográficos 2000 (IBGE).

Para o período 2005/2010 (Figura 3), o Centro-Oeste e o Norte são considerados áreas de retenção de migrantes qualificados, respectivamente com $(0,17)$ e $(0,13)$; já o Sudeste (0,07), Sul $(-0,04)$ e o Nordeste $(-0,02)$ são áreas de rotatividade migratória qualificada. No tocante ao IEM dos estados, são classificados como áreas de retenção de migrantes qualificados: Acre $(0,36)$, Amapá $(0,36)$, Roraima $(0,30)$, Sergipe $(0,18)$, Espírito Santo $(0,14)$, Santa Catarina $(0,22)$, Distrito Federal $(0,24)$ e Mato Grosso $(0,15)$. Como áreas de rotatividade estão os estados do Rio de Janeiro (-0,11), Alagoas $(-0,08)$, Ceará $(-0,05)$, Amazonas $(-0,03)$, Pará 
$(0,02)$, Goiás $(0,10)$ e Rio Grande do Norte $(0,12)$. Por sua vez, os estados com perdas de migrantes qualificados são Piauí $(-0,25)$, Minas Gerais $(-0,18)$ e o Rio Grande do Sul $(-0,28)$.

No caso de Goiás, segundo Anônimo e Santos (2015), o estado surgiu no cenário nacional como uma das principais fronteiras agrícolas, com o desenvolvimento e expansão da agroindústria, passando a atrair e reter migrantes, sendo o segundo estado em termos de saldo migratório positivo, na migração interestadual brasileira, conforme o Censo Demográfico 2010.

\section{Figura 3 - Classificação do Índice de Eficácia Migratória - Brasil - 2005/2010}

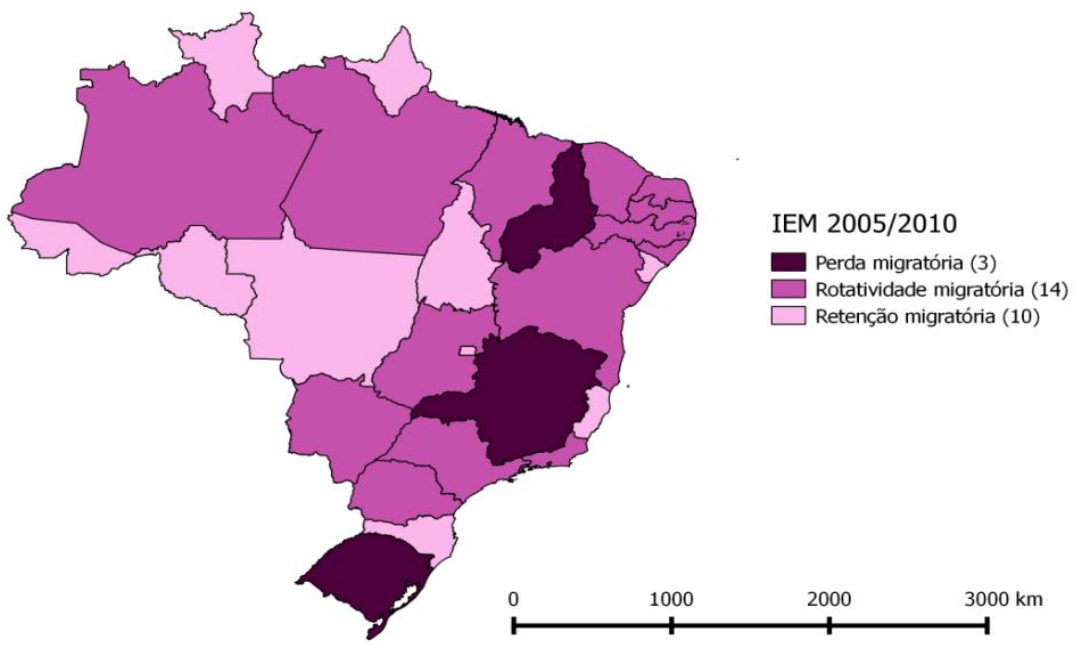

Fonte: Elaboração própria a partir dos microdados das amostras dos Censos Demográficos 2010 (IBGE).

A partir dos três quinquênios analisados sobre o IEM, constata-se o Centro-Oeste como área de retenção de migrantes qualificados no país. Ademais, verifica-se a tendência das regiões e estados serem áreas de rotatividade migratória, visto que em 1986/1991, existiam 13 estados nessa situação, no interregno 1995/2000 foram 12 e, no quinquênio 2005/2010, aumenta para 14 estados.

Isso revela a complexidade de se estudar as migrações internas a partir das décadas de 1980, dado que não há mais um padrão migratório conforme constatado no estudo de Brito (2009), que no período de 1940 até 1980 revelava a predominância dos fluxos interestaduais de longa distância, notadamente do rural para o urbano, e de Minas Gerais e do Nordeste para o Sudeste. No século XXI, as migrações estão mais complexas, com intenso ir e vir, distintas etapas migratórias e inúmeras modalidades migratórias: migração de cérebros/qualificada, migração de retorno, intensificação do fluxo de curta distância (migração intraestadual) e o movimento pendular. 


\section{CONSIDERAÇÕES FINAIS}

O objetivo principal deste estudo foi analisar a migração qualificada entre as entre as 26 Unidades da Federação e o Distrito Federal que compõe o território brasileiro, procurando saber o posicionamento de cada estado na atração ou perda, bem como se o local/UF de origem e de destino segue ou não uma tendência ao longo dos três quinquênios analisados.

Como resultado constatou-se aumento expressivo no volume de migrantes interestaduais qualificados no país, entre 2000 e 2010, resultado da relativa desconcentração da atividade econômica, oportunidades de empregos formais em região menos desenvolvida do país, investimentos em educação superior e ensino técnico profissionalizante, além da interiorização do ensino.

Ademais, durante os três quinquênios analisados, a maioria dos migrantes qualificados se dirigem preferencialmente para a região Centro-Oeste, notadamente o Distrito Federal, principal área de atração do Brasil. Por outro lado, as regiões Sudeste e Sul tipificam como as que mais perdem migrantes qualificados, especialmente os estados do Rio de Janeiro e Rio Grande do Sul. Por sua vez, o Nordeste apresentou-se como uma região que passou por constantes mudanças no saldo migratório de indivíduos qualificados, de área perdedora (1986/1991), a receptora (1995/2000), tornando-se novamente perdedora (2005/2010), mas com um volume não tão intenso quando comparado ao período de 1986/1991.

Quanto ao Índice de Eficácia Migratória, este confirma os resultados encontrados para o Centro-Oeste, particularmente o Distrito Federal, como o principal polo de retenção e atração de pessoas qualificadas no Brasil. Assim como os resultados obtidos para o Sudeste e Sul, que tipificam como áreas de perda/evasão de migrantes qualificados, como também os encontrados para o Nordeste, que se posiciona como região de rotatividade de migrantes qualificados.

Portanto, conclui-se que o capital humano e/ou mão-de-obra qualificada que decide migrar, em geral, busca localidades que ofereçam atrativos como: trabalho, salário, infraestrutura e qualidade de vida. Isto porque, verificou-se aumento no número de migrantes qualificados pelo país, resultado da relativa desconcentração dos postos de trabalho ou oportunidade de empregos em Universidades ou exigência de educação superior em outras áreas/estados do Brasil.

Por último, futuros estudos devem investigar a migração interestadual qualificada para as cidades médias, a fim de verificar se os ganhos ou perdas de migrantes qualificados são significativos, dado que tais áreas/espaços/localidades apresentam características sociais, econômicas, demográficas e educacionais distintas dos estados e grandes metrópoles. 


\section{REFERÊNCIAS}

BAENINGER, Rosana. Migrações internas no Brasil no século 21: entre o local e o global. In: Anais do XVIII Encontro Nacional de Estudos Populacionais, Águas de Lindóia - SP, 2012. Disponível em: <

http://www.abep.org.br/publicacoes/index.php/anais/article/viewFile/1992/1949 >. Acesso em: 17/02/2017.

BEZERRA, Fernanda Mendes; SILVEIRA NETO, Raul da Mota. Existe "fuga de cérebros" no Brasil? Evidências a partir do censo demográfico de 1991 e 2000. Revista Economia, Brasília (DF), v.9, n.3, p.435-456, 2008. Disponível em: < http://www.anpec.org.br/revista/vol9/vo19n3p435_456.pdf >. Acesso em: 16/03/2016.

BRITO, Fausto. As migrações internas no Brasil: um ensaio sobre os desafios recentes. In: VI Encontro Nacional sobre Migrações, 2009, Belo Horizonte. Anais do VI Encontro Nacional sobre Migrações. Campinas: ABEP, v. 1, 2009. Disponível em: <

http://www.abep.nepo.unicamp.br/docs/anais/outros/6EncNacSobreMigracoes/ST3/FaustoBri Fa.pdf > . Acesso em: 21/05/2017.

CAMPOS, João Paulo de Souza. Mobilidade geográfica de trabalhadores qualificados: principais evidências para o Brasil e o Espírito Santo. 2014. Dissertação (Mestrado em Economia) - Centro de Ciências Jurídicas e Econômicas, Universidade Federal do Espírito Santo. Disponível em: <

http://repositorio.ufes.br/bitstream/10/1290/1/Disserta\%C3\%A7\%C3\%A3o\%20Jo\%C3\%A3o $\% 20$ Paulo\%20de\%20Souza\%20Campos.pdf >. Acesso em: 18/03/2016.

CARVALHO, Rodrigo Coelho de.; RIGOTTI, José Irineu Rangel. O efeito das migrações na estrutura etária e no crescimento populacional das cidades médias de Minas Gerais no período 1980-2010. In: Anais do XIX Encontro Nacional de Estudos Populacionais (ABEP), p. 121, 2016. Disponível em: < http://www.abep.org.br/publicacoes/index.php/anais/article/view/2139/2095 >. Acesso em: $15 / 03 / 2017$.

CARVALHO, Cícero Péricles de Oliveira. Nordeste: sinais de um novo padrão de crescimento (2000/2008). Revista Economia Política do Desenvolvimento, v. 1, n. 2, p. 7 , 2010.

CUNHA, José Marcos Pinto da; BAENINGER, Rosana. Cenários da migração no Brasil nos anos 90. Cadernos do CRH (UFBA), Salvador, v. 18, n. 43, 2005.

DA MATA, Daniel et al (2007). Quais características das cidades determinam a atração de migrantes qualificados?. Texto para Discussão IPEA, n. 1305. Disponível em: < http://www.ipea.gov.br/portal/index.php?option=com_content\&view=article\&id=4872 >. Acesso em: 11/03/2016.

DELICADO, Ana. O retorno dos "cérebros": regresso e reintegração dos investigadores portugueses em mobilidade. Revista Iberoamericana de Ciencia, Tecnología y Sociedad, v. 
15, n. 5, p. 185-185, 2010. Disponível em: < http://www.oei.es/historico/revistactsi/ >. Acesso em: $23 / 06 / 2016$.

GOLGHER, André Braz; ROSA, Carlos Henrique; ARAÚJO JÚNIOR, Ari Francisco de. The determinants of migration in Brazil. Texto para discussão $\mathbf{n}^{\mathbf{0}}$ 268. Belo Horizonte: UFMG/ CEDEPLAR, 2005. Disponível em: < http://www.cedeplar.ufmg.br/pesquisas/td/TD\%20268.pdf > . Acesso em: 21/04/2017.

GONÇALVES, Eduardo RIBEIRO, Danielle Reis de Souza; FREGUGLIA, Ricardo da Silva. Migração de mão de obra qualificada e inovação: um estudo para as microrregiões brasileiras. In: XL Encontro Nacional de Economia, Porto de Galinhas (PE), 2012. Disponível em: < https://www.anpec.org.br/encontro/2012/inscricao/files_I/i9af66043f5d157ca63e58b40593bac0d6.pdf >. Acesso em: 0/03/2016.

GUIMARÃES, Reinaldo. Diáspora: Um Estudo Exploratório sobreo Deslocamento Geográfico de Pesquisadores Brasileiros na Década de 90. Dados [online]. Revista de Ciências Sociais, Rio de Janeiro, V. 45, n.4, pp. 705-750, 2002. Disponível em: < http://www.scielo.br/scielo.php?pid=S001152582002000400006\&script=sci_abstract\&tlng=es >. Acesso em: 04/03/2016.

HAUPT, Alexander; KRIEGER, Tim; LANGE, Thomas. Education policy, student migration, and brain gain. Discussion Paper Series, Wilfried Guth Endowed Chair for Constitutional Political Economy and Competition Policy, University of Freiburg, No. 2013-05, January 2013. Disponível em: < https://www1.plymouth.ac.uk/research/cemlef/Documents/Haupt_Krieger_Lange_2013_Educ ation_Migration_Brain_Gain_Jan_2013_WP_Final.pdf >. Acesso em: 11/08/2016.

BRITO, Fausto; HORTA, Cláudia Júlia G. Minas Gerais: crescimento demográfico, migrações e distribuição espacial da população. In: Anais do X Seminário sobre a Economia Mineira [Proceedings of the 10th Seminar on the Economy of Minas Gerais]. Cedeplar, Universidade Federal de Minas Gerais, 2002. Disponível em: < https://ideas.repec.org/h/cdp/diam02/200256.html >. Acesso em: 15/03/2017.

IBGE. Microdados do Censo Demográfico de 1991, 2000 e 2010.

IPEA. (2014). O vaivém dos cérebros migrantes. Revista desafios do desenvolvimento [online]. Edição 80, ano 10. Disponível em: <

http://desafios.ipea.gov.br/index.php?option=com_content $\&$ view $=$ article $\&$ id=3042\&catid=28 \&Itemid=39 > . Acesso em: 10/03/2017.

JARDIM, Maria de Lourdes; BARCELLOS, Tanya Maria Macedo de. Migrações no Rio Grande do Sul. Revista Paranaense de Desenvolvimento, n. 121, p. 133-147, 2011. Disponível em: < https://dialnet.unirioja.es/servlet/articulo?codigo=3946435 >. Acesso em: $15 / 03 / 2017$.

LEE, Jenny J., KIM, Dongbin. Brain gain or brain circulation? US doctoral recipients returning to South Korea. Higher Education, v. 59, n. 5, p. 627-643, 2010. Disponível em: < http://link.springer.com/article/10.1007/s10734-009-9270-5?view=classic >. Acesso em: 05/04/2016. 
MIYAGIWA, Kaz. Scale Economies in Education and the Brain Drain Problem. International Economic Review, v. 32, n. 3, p. 743-759, 1991. Disponível em: < https://www.academia.edu/597388/Scale_economies_in_education_and_the_brain_drain_pro blem >. Acesso em: 20/03/2016.

OLIVEIRA, Antônio Tadeu Ribeiro de; ERVATTI, Leila Regina. Mobilidade espacial da população no Rio de Janeiro: dinamismo e estagnação. In: XVIII Encontro Nacional de Estudos Populacionais (ABEP), Águas de Lindóia/SP, 2012. Disponível em: < http://www.abep.nepo.unicamp.br/xviii/anais/files/ST32[98]ABEP2012.pdf > . Acesso em: 15/03/2017.

OLIVEIRA, Luiz Antonio Pinto; OLIVEIRA, Antônio. Tadeu Ribeiro. (Ed.) Reflexões sobre os deslocamentos populacionais no Brasil. 1. ed. Rio de Janeiro: Fundação IBGE, v. 1. 103p, 2011.

ÖZDEN, Çaglar. Educated migrants: is there brain waste? SCHIFF, Maurice; ÖZDEN, Çaglar (Ed.). In: International migration, remittances, and the brain drain, The Word Bank $\mathrm{p}$. 227-244, 2006. Disponível em: < http://documents.worldbank.org/curated/en/426881468127174713/310436360_20050929711 5833/additional/339880rev.pdf >. Acesso em: 29/03/2016.

PORTES, Alejandro. Determinants of the Brain Drain. International Migration Review, vol. 10, n.4, p. 489-508, 1976. Disponível em: <

http://www.jstor.org/stable/2545081?seq=1\#page_scan_tab_contents >. Acesso em: 02/03/2016.

Anônimo; SANTOS, José Márcio. Os Fluxos Migratórios do Estado de Goiás no Período Recente: 1986-2010. Conjuntura Econômica Goiana, v. 1, p. 21-36, 2015.

SABBADINI, Ricardo; AZZONI, Carlos Roberto. Migração interestadual de pessoal altamente educado: evidências sobre a fuga de cérebros. Encontro Nacional de Economia, v. 34, n. 5, 2006. Disponível em: <

http://www.anpec.org.br/encontro2006/artigos/A06A026.pdf>. Acesso em: 09/08/2016.

SCHNEIDER, Raquel Aline; HENRIQUE, Jonas da Silva. Há Fuga de Cérebros (Brain Drain) nas Microrregiões Paranaenses? In: Anais - VII Seminário Internacional Sobre Desenvolvimento Regional - VII SIDR, Santa Cruz do Sul - RS, 2015. Disponível em: < https://online.unisc.br/acadnet/anais/index.php/sidr/article/viewFile/13387/2552 >. Acesso em 25/03/2016.

SCHWARTZMAN, Simon et al. Projeto Retorno: avaliação do impacto do treinamento no exterior de pessoal qualificado. Relatório Final da Pesquisa, Rio de Janeiro, 1972. Disponível em: < https://archive.org/stream/ProjetoRetornoEmpregadores/mlucia\#page/n1/mode/2up >. Acesso em: 13/08/2016.

"Brain-Drain: Pesquisa Multinacional?", in E. O. Nunes (org.), A Aventura Sociológica - Objetividade, Paixão, Improviso e Método na Pesquisa Social. Rio de Janeiro, Zahar Editores, Biblioteca de Ciências Sociais, 1978. Disponível em: http://www.schwartzman.org.br/simon/bdrain.htm . Acesso em: 13/08/2016. 
SERRANO, Agnes de França et al. A migração como fator de distribuição de pessoas com alta escolaridade no território brasileiro. Brasil em desenvolvimento 2013: estado, planejamento e políticas públicas, Instituto de Pesquisa Econômica Aplicada (IPEA); editores: Rogério Boueri, Marco Aurélio Costa. - Brasília: IPEA, Cap. 21, p. 633, 2013. Disponível em: < http://repositorio.ipea.gov.br/bitstream/11058/3941/1/Livro-

Brasil_em_desenvolvimento_2013_v_3.pdf >. Acesso em: 20/11/2016

SJAASTAD, Larry A. The cost and returns of human migration. Journal of Political Economy, v. 70, p. 80-93, 1962.

SOLIMANO, Andrés. The international mobility of talent and its impact on global development: an overview. Serie Macroeconomía del Desarrollo, Santiago, n. 52, p. 1-35, 2006.

TAVEIRA, Juliana Gonçalves; GONÇALVES, Eduardo; FREGUGLIA, Ricardo da Silva. Uma análise da mobilidade de trabalhadores qualificados da indústria de transformação brasileira. Revista Econômica Contemporânea, Rio de Janeiro, v. 15, n. 2, p. 243-270, 2011. Disponível em: < http://search.proquest.com/openview/21b0728340191cc27fe4e3d793e6cb04/1.pdf?pqorigsite $=$ gscholar $\& \mathrm{cbl}=756358>$. Acesso em: 12/03/2016.

TAVEIRA, Juliana Gonçalves; ALMEIDA, Eduardo Simões de. Os determinantes regionais da atração do migrante qualificado. Análise Econômica, v. 32, n. 62, 2012. Disponível em: < http://www.seer.ufrgs.br/AnaliseEconomica/article/view/23015/0 >. Acesso em: 03/03/2016.

TORRES, Marina Monteiro. Migração de cérebros e acumulação de capital dos municípios brasileiros. 2016. 104f. Dissertação (Mestrado em economia) - UFPB, João Pessoa. Disponível em: < http://tede.biblioteca.ufpb.br/handle/tede/8320 >. Acesso em: 09/08/2016.

Recebido em Julho de 2020

Aprovado em Julho de 2020

Publicado em Fevereiro de 2021 